\title{
UM DIA SEM COPO PLÁSTICO NO RESTAURANTE UNIVERSITÁRIO DA UNIVERSIDADE FEDERAL DO ESPÍRITO SANTO, CAMPUS ALEGRE ES
}

\author{
Renata Figueira Alixandre de Carvalho ${ }^{1}$ \\ Andressa Hartuiq dos Santos ${ }^{2}$ \\ Kelmer Mozer Moro ${ }^{3}$ \\ Anderson Lopes Peçanha ${ }^{4}$
}

Resumo: O problema ambiental causado pelo consumo excessivo de copos plásticos é de conhecimento geral, mas ocorre de forma intensa nos ambientes universitários. Os copos são produtos derivados do petróleo, cuja desde a sua produção até o seu transporte, causa impactos ambientais. Pensando nisso, este trabalho teve como o objetivo, apresentar uma solução para grande demanda de copos exigida pelo Restaurante Universitário (RU) da UFES (Campus Alegre), substituindo os copos plásticos por canecas, visto que entre os meses de março e agosto de 2015 foram gastos aproximadamente 160 mil copos. A ação principal do trabalho foi promover um dia da semana em que o RU não disponibiliza-se copos descartáveis, intitulado de dia da caneca, incentivando o público a levar suas próprias canecas. A campanha ocorreu em três terças-feiras, deixando de gastar cerca de 5400 copos descartáveis. O trabalho teve uma repercussão positiva, foi vantajosa ambientalmente e financeiramente, porém não teve efeito sobre a utilização de canecas por parte do público nos dias que não houve a campanha.

Palavras-chave: Impacto ambiental; Copos plásticos; Canecas; Restaurante universitário.

\footnotetext{
1 Centro de Ciências Exatas, Naturais e da Saúde/Universidade Federal do Espírito Santo. E-mail: renata.figueiraa@gmail.com.

2 Centro de Ciências Exatas, Naturais e da Saúde/Universidade Federal do Espírito Santo. E-mail: andressahartuiq@yahoo.com.br.

3 Centro de Ciências Exatas, Naturais e da Saúde/Universidade Federal do Espírito Santo. E-mail: kelmer.moro@gmail.com.

4 Centro de Ciências Exatas, Naturais e da Saúde/Universidade Federal do Espírito Santo. E-mail: lopes.pecanha@gmail.com.
} 